Check for updates

Cite this: RSC Adv., 2017, 7, 40887

\title{
Synthesis and characterization of amide linked triazolyl glycolipids as molecular hydrogelators and organogelators $\uparrow$
}

\author{
Guijun Wang, (D) *a Anji Chen, (D) ${ }^{a}$ Hari P. R. Mangunuru (D) ${ }^{b}$ \\ and Jayasudhan Reddy Yerabolu (D)
}

\begin{abstract}
Carbohydrate based small molecular gelators are important classes of compounds which can form useful soft materials with many practical applications. Although many different types of effective gelators have been reported, the rational design of a molecular hydrogelator is still challenging. In this research, we combined the structural features of two classes of monosaccharide based molecular gelators and obtained a new class of glycolipids that can function as molecular gelators. These new compounds were synthesized by introducing a triazole functional group to a protected 2-glucosamine through $\mathrm{Cu}(\mathrm{I})$ catalyzed azide/alkyne cycloaddition reaction (CuAAC). A series of eighteen new glycolipids containing 4,6-O-benzylidene acetal protected D-glucosamide and triazole were synthesized and characterized. The self-assembling properties of these compounds were screened in several organic solvents, aqueous solutions, and water. All eighteen compounds are effective molecular gelators for at least one solvent and, more significantly, eleven compounds are hydrogelators with minimum gelation concentrations of 0.15-1.0 wt\%. The hydrogels are suitable carriers for sustained release of chloramphenicol, and for the entrapment of toluidine blue dye. These results indicate that the $\mathrm{D}$-glucosamide triazoles are effective templates for small molecular hydrogelators and are useful in designing sugar based soft materials.
\end{abstract}

Received 4th June 2017

Accepted 27th July 2017

DOI: $10.1039 / \mathrm{c} 7 \mathrm{ra06228a}$

rsc.li/rsc-advances for the preparation of tissue engineering scaffolds and drug delivery vehicles. ${ }^{13-23}$ Many different classes of compounds including natural products have been found to be useful building blocks for effective small molecular gelators. ${ }^{13,24-33}$ Among these, carbohydrate based systems are especially interesting since they can lead to biocompatible and biodegradable soft materials. ${ }^{34-43}$ It is not easy to predict the gelation ability of certain molecules, however it is possible to rationally design new molecular gelators using the existing templates and incorporate important intermolecular interactions. During the past several years, we have synthesized and studied the molecular self-assemblies of many derivatives of common monosaccharides, such as D-glucose and D-glucosamine and gained insights on the requirement of structures for effective molecular gelators. For example, we have shown that certain derivatives of 4,6-benzylidene acetal protected monosaccharides are effective sugar based LMWGs. ${ }^{40,41}$ Several representative structures are shown in Fig. 1. The amide, urea and carbamate analogs obtained from D-glucosamine with the general structure $\mathbf{1}$ are especially effective in forming gels for a variety of polar solvents and aqueous mixtures, but only very few of them are effective gelator for water alone.

$\mathrm{Cu}(\mathrm{I})$ catalyzed azide/alkyne cycloaddition (CuAAC) reaction, the "click chemistry", has found important applications in many research fields such as drug discovery, chemical biology, and materials chemistry. ${ }^{44-46}$ The CuAAC method has been used 


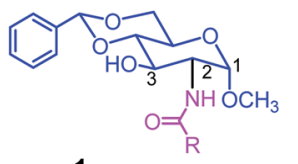

$1 \mathrm{R}=$ NHR", OR", alkyl aryl

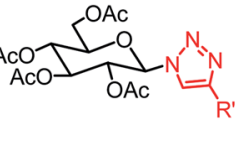

2

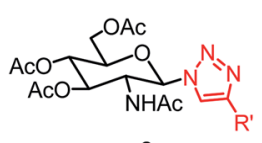

3
Fig. 1 Structures of D-glucose and D-glucosamine based small molecular gelators.

widely in the synthesis of triazole containing glycoconjugates and glycomimetics. ${ }^{47-49}$ Many sugar triazole derivatives were synthesized and studied for their biological applications. Recently we and others have reported several triazole based low molecular weight gelators. ${ }^{\mathbf{5 0 - 5 6}}$ Certain peracetylated D-glucosyl triazoles and D-glucosamine triazole analogues ( 2 and 3 ) are found to be effective gelators and they are able to gelate alcohols, DMSO and water mixtures, ethanol and water mixtures, a few analogs are also effective gelator for water. ${ }^{52,53}$

The glucosyl triazole derivatives 2 are more effective organogelators. Many of the D-glucosamine derivatives 3 with the heterocycle 1,2,3-triazole at the anomeric position and -NHAc at the 2-position are effective hydrogelators. We envisioned that by introducing a triazole functional group to the 2-acyl position of the D-glucosamine derivatives $\mathbf{1}$, it is possible to obtain more effective low molecular weight hydrogelators. By shifting the triazole to the 2-position, we can take advantage of the additional amide hydrogen bonding capacity and the $\pi-\pi$ interaction from the triazole moiety, the combination of these intermolecular noncovalent forces could result in stronger and more effective interactions and gelation. Therefore here we designed and synthesized a series of glycolipids with the above structural features and tested their gelation properties in several solvents.

\section{Results and discussions}

\section{Synthesis of the amide linked triazoles}

The synthesis and structures of the compounds are shown in Scheme 1 and Table 1 . The bromoacetamide intermediate 5 was synthesized from the protected glucosamine headgroup 4 used in our previous synthesis. ${ }^{\mathbf{4 1}}$ Then the azido headgroup 6 was synthesized by displacing the bromide with sodium azide in acetone under refluxing condition. The azido headgroup 6 was then used to react with a variety of alkynes using the CuAAC reaction. Typically these were done using the two commonly used conditions, either by copper sulfate and sodium ascorbate or by CuI in presence of an amine base. The selection of the alkynes is based on our previous results on the glucosyl triazole compounds and the polarity of the compounds. As shown in Scheme 1, we synthesized the 2-glucosamine amide triazole analogs 7-24. The isolated yields of the CuAAC reactions, the subcategories of these compounds, and their $\operatorname{Clog} P$ values are included in Table 1 . These include derivatives containing alkyl groups with different chain lengths (7-12) and aromatic substituents (14-15). We also prepared analogues with terminal functional groups attached to the alkyl groups, including chloro (13), amino (16), hydroxyl (17-21) and carboxyl functional groups (22-23). A dimeric compound 24 was also synthesized by coupling with the dimeric alkyne. These compounds were then tested for their gelation properties in several solvents and the results are shown in Table 2 . The subgroups of the compounds listed in Table 1 will be used for the discussion of structure and gelation property correlations.

\section{Gelation test}

As shown in Table 2, we were pleased to find that these compounds were effective molecular gelators and they were especially effective for water gelation. The gels are typically translucent or transparent and some representative photographs of the gels are shown in Fig. 2. Low molecular weight hydrogelators (LMHGs) are very useful for biomedical applications. In comparison to the peracetylated glycosyl triazole analogs, ${ }^{52,53}$ these glucosamide triazole analogs are more effective hydrogelators. Eleven out of the eighteen compounds synthesized can form hydrogels at low concentrations (0.15-1.0 wt\%). All synthesized compounds except 18 and 20 formed gels in DMSO and water (1:2) mixture, and all compounds except 11, 14, and
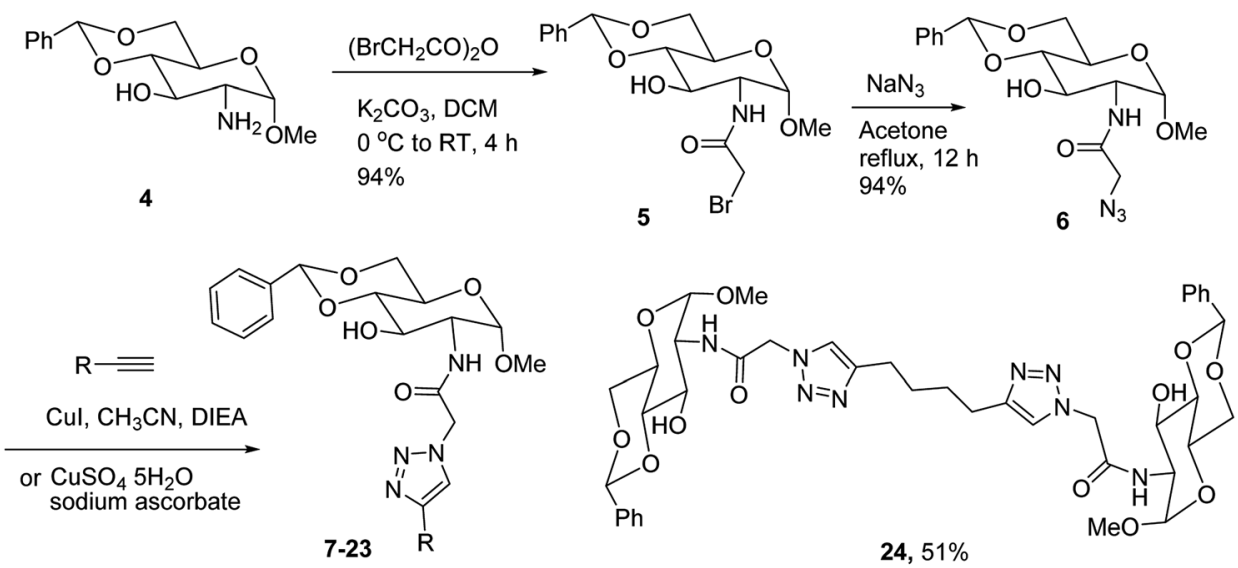

$\mathrm{R}=$ alkyl aryl etc see Table 1

Scheme 1 Synthesis of compounds 7-24 from the glucosamine derivative 4 . 
Table 1 Structures of the amide linked triazoles and their yields

\begin{tabular}{|c|c|c|c|c|}
\hline Compound no. & $\mathrm{Clog} P$ & $\mathrm{R}=$ & Subcategories & Yields \\
\hline 7 & 0.73 & & Alkyl-C3 & $85 \%$ \\
\hline 8 & 2.32 & & Alkyl-C6 & $85 \%$ \\
\hline 9 & 3.91 & & Alkyl-C9 & $81 \%$ \\
\hline 10 & 4.44 & & Alkyl-C10 & $78 \%$ \\
\hline 11 & 6.55 & & Alkyl-C14 & $77 \%$ \\
\hline 12 & 0.96 & & Alkynyl-C4 & $79 \%$ \\
\hline 13 & 0.97 & & Chloro-C4 & $86 \%$ \\
\hline 14 & 1.50 & & Phenyl- & $90 \%$ \\
\hline 15 & 2.15 & & Phenyl-C3 & $87 \%$ \\
\hline 16 & -0.76 & & Amino-C1 & $79 \%$ \\
\hline 17 & -2.31 & & Hydroxyl-C1 & $72 \%$ \\
\hline 18 & -1.63 & & Hydroxyl-C2 & $84 \%$ \\
\hline 19 & -1.25 & & Hydroxyl-C3 & $77 \%$ \\
\hline 20 & 0.39 & & Hydroxyl-C(6) & $78 \%$ \\
\hline 21 & 1.92 & & Hydroxyl-C9 & $88 \%$ \\
\hline 22 & -0.16 & & Carboxyl-C4 & $72 \%$ \\
\hline 23 & 1.96 & & Carboxyl-C8 & $65 \%$ \\
\hline 24 & -0.29 & & Dimer C-4 & $51 \%$ \\
\hline
\end{tabular}

18 formed gels in ethanol and water mixtures. These results are significant since we can predicate that other suitable analogs with this type of template will be able to form gels in water and aqueous solutions.

\section{Structure and gelation properties}

Among the alkyl derivatives 7-11, only the short chain propyl derivative 7 was able to form a hydrogel. When the compounds contain linear aliphatic chain spacer with terminal functional groups, they are effective hydrogelators, these include alkynyl (12), chloro (13), phenyl (15), dimethyl amino (16), hydroxyl (17, $18,19,21)$, carboxyl $(22,23)$. The best performing hydrogelator is the propyl derivative 7 , which formed hydrogels at $0.15 \mathrm{wt} \%$ concentration and also formed gels in mixtures of ethanol or DMSO with water. The phenyl triazole compound $\mathbf{1 4}$ and cyclohexanol derivative $\mathbf{2 0}$ have no alkyl spacer between triazole and the functional groups, and they did not form hydrogels. Interestingly; compound $\mathbf{2 0}$ was the only one formed a stable gel in toluene. None of these compounds formed gels in dichloromethane, and they were all insoluble in hexane. The alkyl derivatives are more effective gelators for alcohols, compounds 9-11 with nine, ten and fourteen carbon chain respectively, can form gels in both ethanol and isopropanol. The phenyl derivative 14 was effective gelator for ethanol, and the dimeric compound 24 was effective gelator for both ethanol and isopropanol. 
Table 2 Gelation test results for the library compounds in several solvents ${ }^{a}$

\begin{tabular}{|c|c|c|c|c|c|c|c|c|}
\hline No. & Hexane & Toluene & DCM & i-PrOH & EtOH & EtOH : $\mathrm{H}_{2} \mathrm{O}(1: 2)$ & DMSO : $\mathrm{H}_{2} \mathrm{O}(1: 2)$ & $\mathrm{H}_{2} \mathrm{O}$ \\
\hline 7 & I & UG 20.0 & S & S & $\mathrm{G} 10.0_{\mathrm{O}}$ & $\mathrm{G} 10.0_{\mathrm{O}}$ & G $5.0_{\mathrm{T}}$ & G $1.5_{T}$ \\
\hline 8 & I & $S$ & $\mathrm{~S}$ & S & $\mathrm{S}$ & $\mathrm{G} 1.4_{\mathrm{O}}$ & $\mathrm{G} 1.0_{\mathrm{O}}$ & I \\
\hline 10 & I & I & $\mathrm{S}$ & G $20.0_{\mathrm{O}}$ & G $20.0_{\mathrm{O}}$ & $\mathrm{G} 1.4_{\mathrm{O}}$ & $\mathrm{G} 1.1_{\mathrm{O}}$ & I \\
\hline 11 & I & UG $10.0_{\mathrm{C}}$ & $\mathrm{P}$ & G $6.7_{C}$ & $\mathrm{G} 4.0_{\mathrm{O}}$ & I & G $5.0_{\mathrm{O}}$ & I \\
\hline 12 & I & $\mathrm{P}$ & $\mathrm{S}$ & $\mathrm{S}$ & $\mathrm{S}$ & $\mathrm{G} 4.0_{\mathrm{T}}$ & G $20.0_{\mathrm{T}}$ & G $5.0_{\mathrm{T}}$ \\
\hline 15 & I & $\mathrm{S}$ & $\mathrm{S}$ & $P$ & $\mathrm{~S}$ & $\mathrm{G} 1.7_{\mathrm{T}}$ & G $2.0_{\mathrm{T}}$ & G $5.0_{\mathrm{T}}$ \\
\hline 16 & I & S & I & G $20.0_{\mathrm{T}}$ & $\mathrm{S}$ & $\mathrm{G} 10.0_{\mathrm{O}}$ & G $20.0_{O}$ & $\mathrm{G} 4.0_{\mathrm{O}}$ \\
\hline 17 & I & I & I & G $20.0_{\mathrm{T}}$ & $\mathrm{S}$ & $\mathrm{G} 6.7_{\mathrm{O}}$ & $\mathrm{G} 10.0_{\mathrm{O}}$ & $\mathrm{G} 2.2_{\mathrm{O}}$ \\
\hline 18 & I & I & I & $\mathrm{P}$ & $\mathrm{P}$ & $\mathrm{P}$ & $\mathrm{P}$ & $\mathrm{G} 1.8_{\mathrm{T}}$ \\
\hline 19 & I & I & I & $S$ & $\mathrm{~S}$ & G $10.0_{\mathrm{T}}$ & UG $20.0_{\mathrm{T}}$ & G $2.0_{\mathrm{T}}$ \\
\hline 20 & I & G $3.3_{\mathrm{C}}$ & S & S & $\mathrm{S}$ & G $5.0_{\mathrm{O}}$ & $\mathrm{P}$ & $\mathrm{P}$ \\
\hline
\end{tabular}

${ }^{a} \mathrm{G}$, gel at room temperature, the numbers are the corresponding minimum gelation concentrations (MGCs) in $\mathrm{mg} \mathrm{mL}^{-1}$; $\mathrm{C}, \mathrm{transparent}$; , translucent; O, opaque; UG, partial gel or unstable gel; I, insoluble; P, crystallize or precipitate; S, soluble at $\sim 20 \mathrm{mg} \mathrm{mL}^{-1}$.

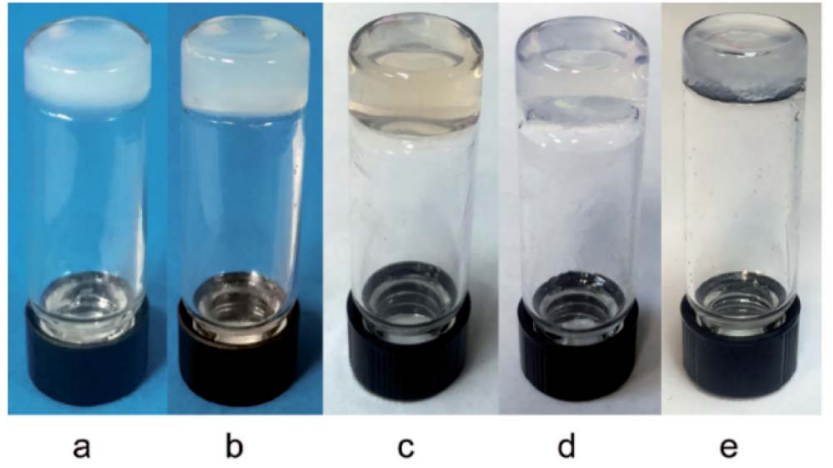

Fig. 2 (a) A translucent gel formed by compound 7 in $\mathrm{H}_{2} \mathrm{O}$ at $1.5 \mathrm{mg} \mathrm{mL}^{-1}$; (b) a translucent gel formed by compound 9 in DMSO : $\mathrm{H}_{2} \mathrm{O}$ ( $v 1: 2$ ) at $1.1 \mathrm{mg} \mathrm{mL}^{-1}$; (c) a transparent gel formed by compound 21 in EtOH : $\mathrm{H}_{2} \mathrm{O}$ ( $v 1$ : 2) at $2.0 \mathrm{mg} \mathrm{mL}^{-1}$; (d) a transparent gel formed by compound 23 in water at $2.0 \mathrm{mg} \mathrm{mL}^{-1}$; (e) a translucent gel formed by compound 24 in ethanol at $2.5 \mathrm{mg} \mathrm{mL}^{-1}$.

There is a strong correlation between the gelation properties and their structures among these 4-triazole-alkyl derivatives. We attempt to obtain a rationale using computed $\operatorname{Clog} P$ values, these are shown in Table 1 next to the compound numbers. When $\mathrm{R}$ is an alkyl group as in compounds 7-12 and an alkyl with non-polar substituent (13), the $\operatorname{Clog} P$ values correlate to the hydrogelation very nicely. Compounds 7, 12, and 13 are effective hydrogelators and their $C \log P$ values are lower than 1.0. For compounds with different substituents such as aryl and polar functional groups, the $\operatorname{Clog} P$ values don't agree with gelation properties well, and it can't give meaningful interpretation for hydrogelation. Despite the limitation, for aliphatic functional groups, it may be possible to use the Clog $P$ values to predict hydrogelation outcomes.
Based on the analysis of the gelation properties, we can easily see that the addition of triazole moiety to the glucosamide analogs led to enhanced gelation results. In comparison to our previous observations of the amide derivatives without triazole moiety, ${ }^{41}$ the current compounds are more effective as LMHGs. It is interesting that many of the triazole analogs are not only hydrogelators they are also effective organogelators. As shown in Table 2, these amide triazole derivatives are very effective organogelators for ethanol and water or DMSO and water mixtures. All compounds but two alcohol analogs are gelators for DMSO and water mixtures. In order to find out the performance of the gelators in a mixture of solvents, we tested the gelation behaviour of a few selected compounds in different ratios of DMSO and water. Table $\mathrm{S} 1 \uparrow$ shows the performance of these compounds at different proportions of DMSO and water mixtures. The most effective hydrogelator compound 7 is also the smallest among the analogs synthesized in Scheme 1. It not only formed hydrogel in water at $1.5 \mathrm{mg} \mathrm{mL}^{-1}$, but also formed stable gels at different proportions of DMSO and water mixture, from $33 \%$ DMSO aqueous mixture up to $4.5 \%$ DMSO aqueous mixture.

\section{Gel characterizations}

We also analyzed the morphology of the gels under an optical microscope. Fig. 3 shows the optical micrographs of the lightly air dried gels formed by compounds $7, \mathbf{9}, \mathbf{1 1}$, and 23. Compound 7 formed translucent hydrogel (Fig. 2a), the partially dried gels showed some fibrous formation but still contained water (Fig. 3a). Compound 9 in EtOH : $\mathrm{H}_{2} \mathrm{O}(\mathrm{v} 1: 2)$ showed birefringent long and curved fibers with average diameters of $0.5 \mu \mathrm{m}$ (Fig. 3b). The long chain analog 11 in EtOH exhibited similar fibrous network (Fig. 3c) but seems to have more crosslinks between the fibers. Compound 23 with a terminal carboxyl 


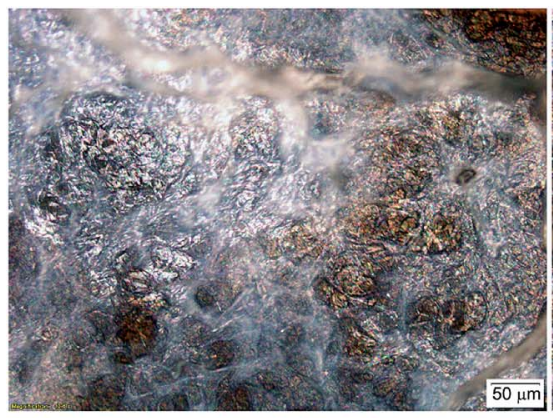

a

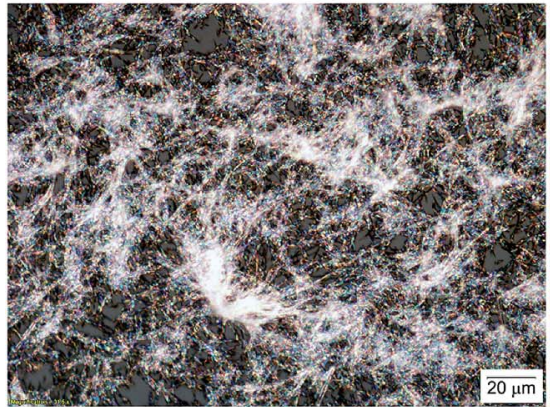

C

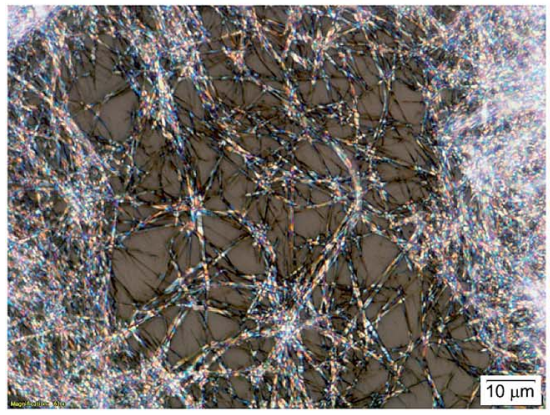

e

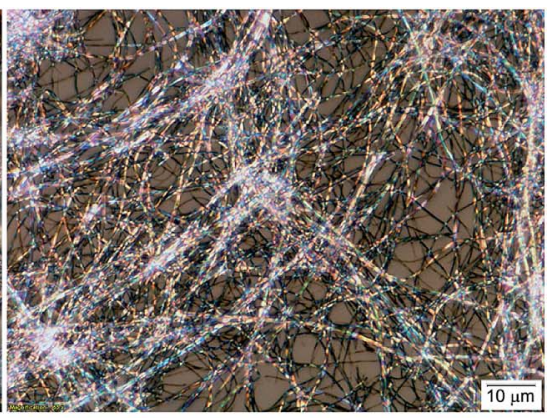

b

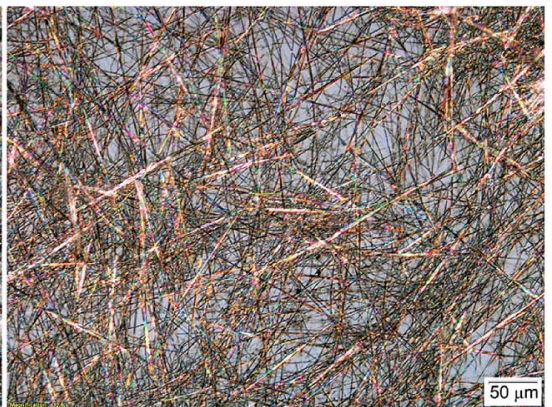

d

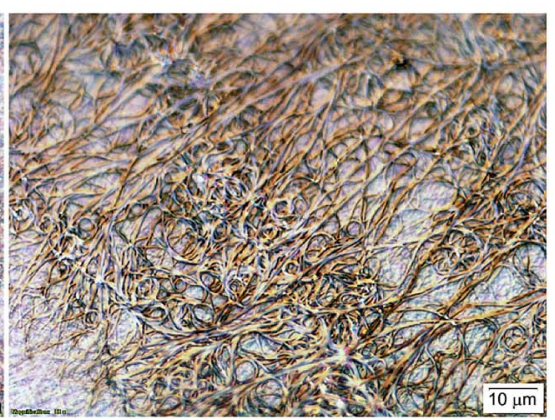

f

Fig. 3 Optical micrographs of the gels formed by several compounds: (a) compound 7 in $\mathrm{H}_{2} \mathrm{O}$ at $1.5 \mathrm{mg} \mathrm{mL}^{-1}$; (b) compound 9 in EtOH : $\mathrm{H}_{2} \mathrm{O}$ ( $\mathrm{v}$ $1:$ ) at $3.3 \mathrm{mg} \mathrm{mL}^{-1}$; (c) compound 11 in EtOH at $4.0 \mathrm{mg} \mathrm{mL}^{-1}$; (d) compound 23 in DMSO : $\mathrm{H}_{2} \mathrm{O}$ (v $1: 2$ ) at $2.8 \mathrm{mg} \mathrm{mL}^{-1}$; (e) compound 23 in

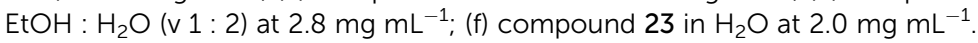

group exhibited versatile gelation properties in several solvents and water. The morphologies of the gels seems to differ based on the solvent systems (Fig. 3d-f). The DMSO : $\mathrm{H}_{2} \mathrm{O}$ ( $\mathrm{v} 1: 2$ ) gel showed very long and straight fibers with average length over 500 $\mu \mathrm{m}$ and a distribution of widths ranging from $0.5-1.5 \mu \mathrm{m}$. These long rods and cylindrical tubes are not uniform perhaps due to the drying process that certain solvent evaporated faster for certain areas. In the EtOH : $\mathrm{H}_{2} \mathrm{O}$ ( $\left.\mathrm{v} 1: 2\right)$ gel of compound 23, the morphology (Fig. 3e) is very similar to that of the alkyl analog 9 as shown in Fig. 3b; the gels also formed long and soft fibrous network, with uniform and narrow width $(\sim 0.5 \mu \mathrm{m})$. The hydrogel formed by 23 showed interesting curled fibrous network and densely packed fibrous assemblies (Fig. 3f), in contrast to the aqueous mixtures, the hydrogels appear not birefringent. The interconnected fibers are uniform in size with diameters about $0.2 \mu \mathrm{m}$.
To analyze the strength of the gels, we studied the rheological properties of a few gels. The dynamic moduli $G^{\prime}$ and $G^{\prime \prime}$ were measured and plotted as a function of angular frequency $\omega$ at their MGCs for compounds 7, 13 and 21. As shown in Fig. 4, the storage modulus $G^{\prime}$ is greater than the loss modulus $G^{\prime \prime}$ for all these gelators. The fact that $G^{\prime}$ is greater than $G^{\prime \prime}$ is an indication that the gels are elastic semisolid. The gel formed by chlorobutyl analog 13 exhibited the largest storage modulus among three tested gels.

\section{Controlled release of drugs}

Because of the excellent gelation abilities in water, these compounds can have important biological applications. We analyzed the effectiveness of the molecular hydrogels for controlled release from gel to solution phase as a proof of concept study. The gel formed by compound 7 was selected for 


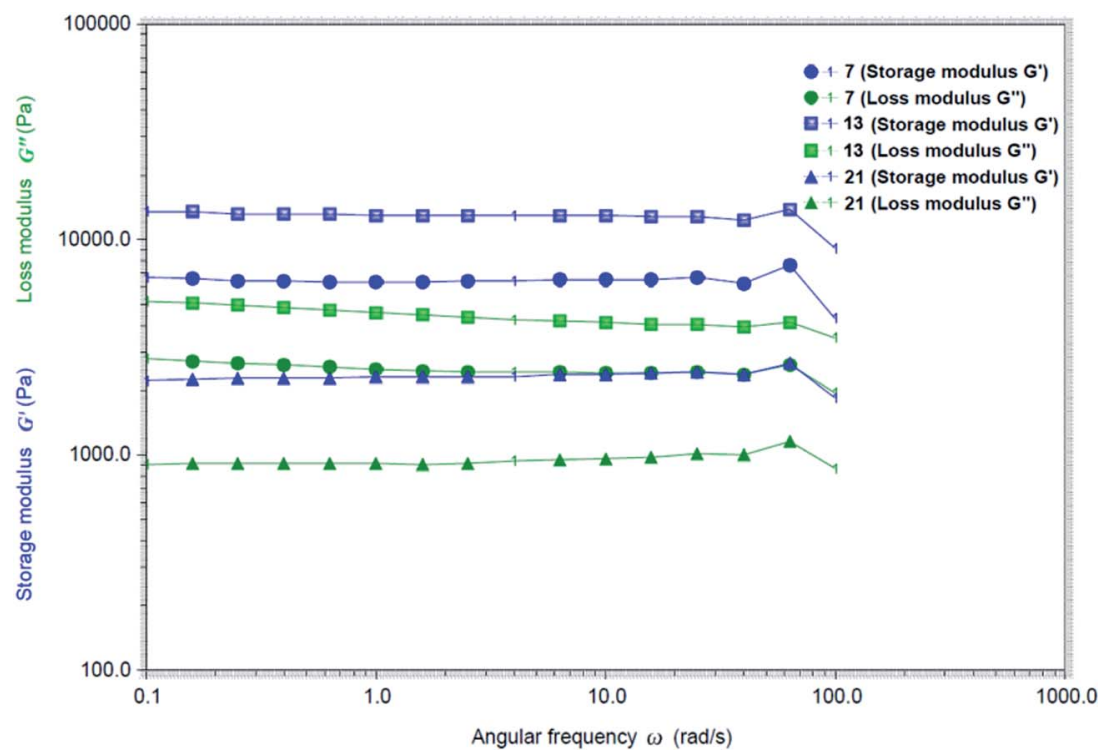

Fig. 4 Rheological properties of the gels formed by compounds 7 in $\mathrm{H}_{2} \mathrm{O}$ at $1.5 \mathrm{mg} \mathrm{mL}^{-1}, 13$ in EtOH : $\mathrm{H}_{2} \mathrm{O}$ (v $\left.1: 2\right)$ at $2.0 \mathrm{mg} \mathrm{mL}^{-1}$ and 21 in $\mathrm{H}_{2} \mathrm{O}$ at $2.0 \mathrm{mg} \mathrm{mL}^{-1}$.

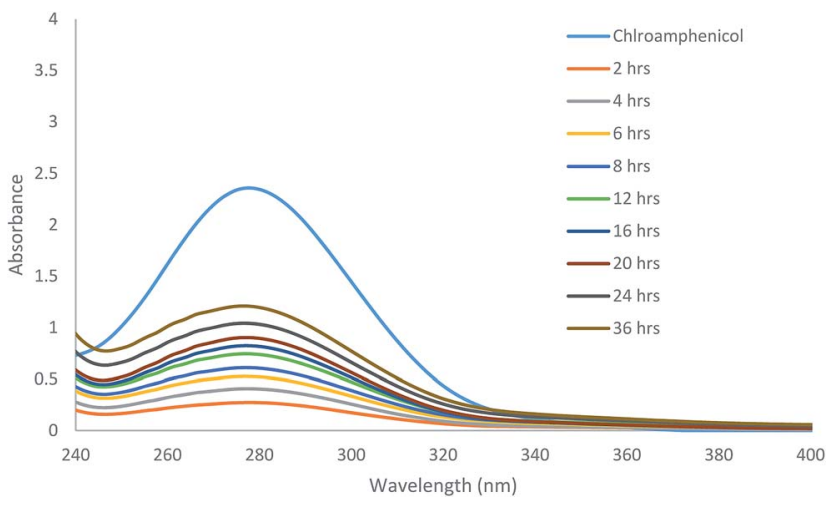

Fig. 5 Release of chloramphenicol from the hydrogel formed by compound 7 to the aqueous phase. Gel was formed by compound 7 (2 mg) and chloramphenicol (0.25 mg) in water (1.4 mL). Chloramphenicol control was prepared by dissolving chloramphenicol $(0.25 \mathrm{mg})$ in water $(3 \mathrm{~mL})$.

controlled release of antibiotic chloramphenicol from the gel matrix. UV spectroscopy was used for the study, the results are shown in Fig. 5. The hydrogel formed by gelator 7 at its MGC in presence of chloramphenicol showed that the gel was stable for encapsulating the drug, which was only slowly released, about $70 \%$ in a period of 36 hours was released to the aqueous phase through diffusion (Fig. S1 and S2†). This indicates that the gel is suitable as carrier for sustained release of small molecule drugs.

We also analysed the diffusion and absorption of a dye onto the gel matrix. The toluidine blue absorption using the hydrogelator $\mathbf{1 3}$ is shown in Fig. 6. The toluidine blue was slowly absorbed by the gel matrix in 3 days (Fig. S3 $\uparrow$ ). At equilibrium, the concentrations of the dye in the gel phase and solution

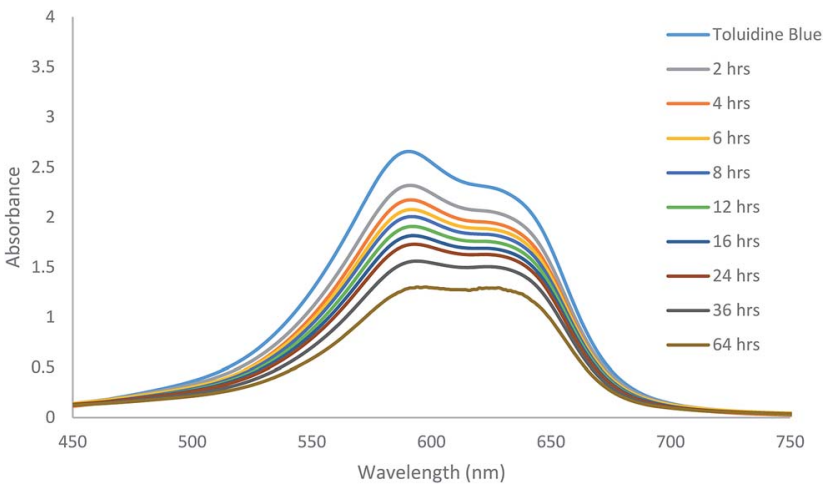

Fig. 6 UV-Vis spectra of toluidine blue solution on top of the hydrogel of compound $13(5 \mathrm{mg})$ in water $(2 \mathrm{~mL})$. The blue curve is the standard toluidine dye solution ( $2 \mathrm{~mL}, 0.1 \mathrm{mM}$ ) before adding to the hydrogel.

phase were almost the same, this implies that the hydrogel is permeable with the dye molecules to diffuse freely and therefore it is suitable for entrapping toluidine blue type of dyes or drugs.

\section{Conclusions}

In summary, we have designed and synthesized a new series of sugar based low molecular weight organogelators and hydrogelators using 4,6-O-benzylidene acetal protected D-glucosamine and "click" reactions. Among the eighteen compounds synthesized and studied, all can form gels in at least one of the tested solvents, and many of them formed hydrogels at 0.15-1.0 $\mathrm{wt} \%$. The structures of the hydrogelators indicate that a delicate balance of hydrophobic and hydrophilic functional groups must be maintained for effective gelation. When the substituents at the C-4 position of the triazole is an alkyl group, the Clog $P$ value should be less than 1.0 in order for the compounds 
to be effective hydrogelator. Moreover, when the C-4 triazole substituents contain a terminal polar functional group, they are also effective hydrogelators. The hydrogels formed by compound 7 are suitable for sustained release of entrapped chloramphenicol. The dye diffusion study with toluidine blue and gelator 13 shows that the hydrogel is permeable to small molecules and reached equilibrium in about 3 days. These results indicate that the $\mathrm{D}$-glucosamide triazole derivatives are very effective small molecular gelators and can be useful in designing sugar based soft materials for a variety of applications.

\section{Experimental section}

\section{General methods}

All reactions were carried out in oven dried glassware under nitrogen atmosphere. Reagents and solvents were obtained from commercial suppliers from Sigma-Aldrich, VWR, and Fisher and used directly without purifications. All reactions unless otherwise noted were carried out. Flash chromatography was carried out using 230-400 mesh silica gel. Thin-layer chromatography (TLC) analysis was performed with aluminum backed TLC plates (Sigma-Aldrich) with UV and fluorescence indicator and visualized using UV lamp at $254 \mathrm{~nm}$ then stained with PMA solution. ${ }^{1} \mathrm{H}$ NMR and proton-decoupled ${ }^{13} \mathrm{C}$ NMR spectra were obtained with Bruker $400 \mathrm{MHz}$ spectrometers in DMSO- $d_{6}$ or $\mathrm{CDCl}_{3}$. The chemical shifts were reported using $\mathrm{CDCl}_{3} / \mathrm{DMSO}-d_{6}$ as internal standard at 7.26/ $2.50 \mathrm{ppm}$ and at 77.00/39.50 ppm, respectively. The molecular mass was measured using LCMS on an Agilent 6120B Single Quad Mass Spectrometer and LC1260 system.

\section{Gelation test for DMSO and water mixture at different ratios}

In a one dram vial, compound 7 ( $2 \mathrm{mg}$ ) was dissolved in DMSO $(0.05 \mathrm{~mL})$; to this solution, water $(0.45 \mathrm{~mL})$ was added, the mixture was sonicated and heated till homogenous and left standing at rt for 15 minutes. The vial was inverted to observe whether a stable gel formed, if a stable gel formed, then water $(0.1 \mathrm{~mL})$ was added subsequently until a stable gel could not be obtained. Other compounds $(\mathbf{9}, \mathbf{1 3}, \mathbf{1 5}, \mathbf{1 6}, \mathbf{2 1}$, and 23) were tested similarly. The volume ratio of DMSO and water was calculated and the gelation concentrations are included in Table $\mathrm{S} 1$ in the ESI. $\dagger$

\section{Drug encapsulation and release}

Chloramphenicol was trapped into the hydrogel of compound 7 and the release from gel to solution was tested. Compound 7 (2 $\mathrm{mg})$, chloramphenicol $(0.25 \mathrm{mg})$, and water $(1.4 \mathrm{~mL})$ were mixed in a one dram vial, the co-gel was prepared by heating/ sonication and then cooling. After a stable gel was formed the gel was left standing at rt for 2 hours, then water $(3 \mathrm{~mL}, \mathrm{pH} 7)$ was added on top of the gel carefully. Chloramphenicol release from the gel was monitored by UV absorption at certain times by transferring the top aqueous layer with a pipet to a cuvette, after each measurement the aqueous phase was carefully transferred back to the vial containing the gel residue. Photographs were taken at these time points and these are shown in Fig. S1. $\dagger$ The drug release profile at different time course was measured using UV spectroscopy and plotted as shown in Fig. 5 .

\section{Dye diffusion and absorption studies}

Toluidine blue dye was selected for the diffusion study using hydrogel of compound $13(5 \mathrm{mg})$ in water $(2 \mathrm{~mL})$. After a stable gel was formed and left standing for 2 hours, toluidine blue aqueous solution ( $2 \mathrm{~mL}, 0.1 \mathrm{mM}$ ) was added slowly on top of the gel. Photographs were taken at different time course (Fig. S3 $\dagger$ ) followed by the measurement of UV absorption of the top aqueous layer. Adsorption of toluidine blue from aqueous solution to the hydrogel at different time interval was monitored by UV-Vis spectroscopy and the results are shown in Fig. 6.

\section{Synthesis of compound 5}

To a $250 \mathrm{~mL}$ round bottom flask, compound 4 (4.01 g, 14.1 $\mathrm{mmol})$ was dissolved in DCM $(30 \mathrm{~mL})$. To this solution, $\mathrm{K}_{2} \mathrm{CO}_{3}$ $(3.91 \mathrm{~g}, 28.2 \mathrm{mmol})$ was added and the reaction mixture was cooled to $0{ }^{\circ} \mathrm{C}$ followed by addition of bromo acetic anhydride (3.61 g, $14.1 \mathrm{mmol}$, pre-dissolved in DCM) dropwise over a period of 15 minutes. The reaction was stirred at $0{ }^{\circ} \mathrm{C}$ for 2 hours and warmed to room temperature and stirred for an additional 8 hours. Reaction was quenched with saturated $\mathrm{NaHCO}_{3}(50 \mathrm{~mL})$ solution and worked up with DCM/water. Combined organic layers were dried over anhydrous $\mathrm{Na}_{2} \mathrm{SO}_{4}$, filtered, concentrated to give the crude product, which was purified by flash chromatography using eluent from pure DCM to $2 \% \mathrm{MeOH} / \mathrm{DCM}$ to afford the product as a white solid (5.30 g, $94 \%)\left(R_{\mathrm{f}}=0.5\right.$ in $\left.2 \% \mathrm{MeOH} / \mathrm{DCM}\right), \mathrm{mp} 228.0-230.0{ }^{\circ} \mathrm{C} .{ }^{1} \mathrm{H} \mathrm{NMR}$ $\left(400 \mathrm{MHz}, \mathrm{CDCl}_{3}\right) \delta \mathrm{ppm}$ 7.52-7.45 (m, 2H), 7.41-7.33 (m, 3H), $6.78(\mathrm{~d}, J=8.8 \mathrm{~Hz}, 1 \mathrm{H}), 5.56(\mathrm{~s}, 1 \mathrm{H}), 4.74(\mathrm{~d}, J=3.8 \mathrm{~Hz}, 1 \mathrm{H})$, 4.33-4.26 (m, 1H), 4.25-4.17 (m, 1H), 4.00-3.87 (m, 3H), 3.86$3.74(\mathrm{~m}, 2 \mathrm{H}), 3.63-3.56(\mathrm{~m}, 1 \mathrm{H}), 3.44(\mathrm{~s}, 3 \mathrm{H}) ;{ }^{13} \mathrm{C}$ NMR $(100 \mathrm{MHz}$, $\left.\mathrm{CDCl}_{3}\right) \delta 166.5,137.0,129.3,128.3,126.3,102.0,98.7,81.9,70.3$, 68.8, 62.4, 55.5, 54.4, 29.0; LCMS (ESI+) calcd for $\mathrm{C}_{16} \mathrm{H}_{21} \mathrm{BrNO}_{6}$ $[\mathrm{M}+\mathrm{H}]^{+}, 402.0$ found 402.1 .

\section{Synthesis of compound 6}

Compound 5 (5.30 g, $13.1 \mathrm{mmol}$ ) was dissolved in acetone (50 $\mathrm{mL}$ ) in a $250 \mathrm{~mL}$ round bottom flask. To this solution sodium azide ( $3.20 \mathrm{~g}, 0.13 \mathrm{~mol}$ ) was added and the reaction mixture was stirred for 12 hours under refluxing condition. Acetone was removed under reduced pressure and the resulting residue was dissolved in water and then extracted with ethyl acetate. The combined organic layers were washed with brine, dried over anhydrous $\mathrm{Na}_{2} \mathrm{SO}_{4}$, filtered and concentrated to afford the crude. It was then purified by flash chromatography using a gradient of solvent system of EtOAc : hexane from $1: 4$ to $1: 1$. The desired product was obtained as a white solid ( $4.60 \mathrm{~g}, 94 \%)$, $\left(R_{\mathrm{f}}=0.7\right.$ in $70 \%$ EtOAc/hexane). mp 207.0-209.0 ${ }^{\circ} \mathrm{C} .{ }^{1} \mathrm{H}$ NMR $\left(400 \mathrm{MHz}, \mathrm{CDCl}_{3}\right) \delta$ 7.54-7.45 (m, 2H), 7.41-7.31 (m, 3H), 6.62 $(\mathrm{d}, J=9.0 \mathrm{~Hz}, 1 \mathrm{H}), 5.56(\mathrm{~s}, 1 \mathrm{H}), 4.72(\mathrm{~d}, J=3.7 \mathrm{~Hz}, 1 \mathrm{H}), 4.31-$ $4.19(\mathrm{~m}, 2 \mathrm{H}), 4.07$ (d, $J=16.7 \mathrm{~Hz}, 1 \mathrm{H}), 4.01$ (d, $J=16.7 \mathrm{~Hz}, 1 \mathrm{H})$, $3.93(\mathrm{dd} \sim \mathrm{t}, J=9.5 \mathrm{~Hz}, 1 \mathrm{H}), 3.86-3.72(\mathrm{~m}, 2 \mathrm{H}), 3.61-3.54(\mathrm{~m}$, $1 \mathrm{H}), 3.42(\mathrm{~s}, 3 \mathrm{H}) ;{ }^{13} \mathrm{C} \mathrm{NMR}\left(100 \mathrm{MHz}, \mathrm{CDCl}_{3}\right) \delta$ 167.6, 137.0, 
129.3, 128.3, 126.3, 102.0, 98.7, 81.9, 70.2, 68.8, 62.4, 55.4, 53.7, 52.5; LCMS (ESI+) calcd for $\mathrm{C}_{16} \mathrm{H}_{21} \mathrm{~N}_{4} \mathrm{O}_{6}[\mathrm{M}+\mathrm{H}]^{+}, 365.1$ found 365.1 .

\section{Synthesis of compound 7}

Compound 6 ( $83 \mathrm{mg}, 0.22 \mathrm{mmol}$ ) was dissolved in acetonitrile $(5 \mathrm{~mL})$. To this solution, 1-pentyne $(0.033 \mathrm{~mL}, 0.33 \mathrm{mmol})$ was added, followed by adding $\mathrm{CuI}(6.5 \mathrm{mg}, 0.034 \mathrm{mmol})$ and DIEA $(0.19 \mathrm{~mL}, 1.1 \mathrm{mmol})$. The reaction mixture was stirred for 24 hours at room temperature. After complete disappearance of starting material as indicated by TLC or ${ }^{1} \mathrm{H}$ NMR spectroscopy, solvent was removed under reduced pressure. The crude product was purified by column chromatography using eluent from pure DCM to $2 \% \mathrm{MeOH} / \mathrm{DCM}$ to obtain an off-white solid (81 $\mathrm{mg}, 85 \%)$ as the desired product $\left(R_{\mathrm{f}}=0.3\right.$ in $5 \% \mathrm{MeOH} /$ DCM). mp 226.0-228.0 ${ }^{\circ} \mathrm{C}$. ${ }^{1} \mathrm{H}$ NMR (400 MHz, d ${ }_{6}$-DMSO) $\delta 8.44(\mathrm{~d}, J=8.5 \mathrm{~Hz}, 1 \mathrm{H}), 7.77(\mathrm{~s}, 1 \mathrm{H}), 7.49-7.43(\mathrm{~m}, 2 \mathrm{H}), 7.41-$ $7.35(\mathrm{~m}, 3 \mathrm{H}), 5.62(\mathrm{~s}, 1 \mathrm{H}), 5.31(\mathrm{~d}, J=5.6 \mathrm{~Hz}, 1 \mathrm{H}), 5.11(\mathrm{~d}, J=$ $16.3 \mathrm{~Hz}, 1 \mathrm{H}), 5.07$ (d, $J=16.3 \mathrm{~Hz}, 1 \mathrm{H}), 4.66(\mathrm{~d}, J=3.6 \mathrm{~Hz}, 1 \mathrm{H})$, 4.19 (dd, $J=9.9,4.7 \mathrm{~Hz}, 1 \mathrm{H}), 3.91-3.81$ (m, 1H), 3.80-3.59 (m, $3 \mathrm{H}), 3.56-3.47$ (m, 1H), 3.33 (s, 3H), 2.59 (t, $J=7.5 \mathrm{~Hz}, 2 \mathrm{H}), 1.66-$ $1.55(\mathrm{~m}, 2 \mathrm{H}), 0.91$ (t, $J=7.4 \mathrm{~Hz}, 3 \mathrm{H}) ;{ }^{13} \mathrm{C}$ NMR $\left(100 \mathrm{MHz}, \mathrm{d}_{6^{-}}\right.$ DMSO) $\delta 165.8,146.3,137.7,128.8,128.0,126.4,123.3,100.9$, 98.5, 81.7, 67.9, 67.5, 62.5, 54.8, 54.3, 51.3, 27.0, 22.2, 13.6; LCMS (ESI+) calcd for $\mathrm{C}_{21} \mathrm{H}_{29} \mathrm{~N}_{4} \mathrm{O}_{6}[\mathrm{M}+\mathrm{H}]^{+}, 433.2$ found 433.2.

Compounds 8-24 were synthesized by similar methods either with $\mathrm{CuI}$ or $\mathrm{CuSO}_{4}$ as the catalyst, the detailed procedure and characterizations are included in the ESI. $\dagger$

\section{Acknowledgements}

We are grateful to the financial support from National Science Foundation grant CHE\#1313633.

\section{References}

1 P. Terech and R. G. Weiss, Chem. Rev., 1997, 97, 3133-3160.

2 L. A. Estroff and A. D. Hamilton, Chem. Rev., 2004, 104, 12011218.

3 N. M. Sangeetha and U. Maitra, Chem. Soc. Rev., 2005, 34, 821-836.

4 Z. Yang, G. Liang and B. Xu, Acc. Chem. Res., 2008, 41, 315326.

5 X. Yu, L. Chen, M. Zhang and T. Yi, Chem. Soc. Rev., 2014, 43, 5346-5371.

6 S. S. Babu, V. K. Praveen and A. Ajayaghosh, Chem. Rev., 2014, 114, 1973-2129.

7 D. J. Abdallah and R. G. Weiss, Adv. Mater., 2000, 12, 12371247.

8 L. S. Birchall, S. Roy, V. Jayawarna, M. Hughes, E. Irvine, G. T. Okorogheye, N. Saudi, E. De Santis, T. Tuttle, A. A. Edwards and R. V. Ulijn, Chem. Sci., 2011, 2, 1349.

9 L. E. Buerkle and S. J. Rowan, Chem. Soc. Rev., 2012, 41, 60896102.

10 Y. Lan, M. G. Corradini, R. G. Weiss, S. R. Raghavan and M. A. Rogers, Chem. Soc. Rev., 2015, 44, 6035-6058.
11 M. D. Segarra-Maset, V. J. Nebot, J. F. Miravet and B. Escuder, Chem. Soc. Rev., 2013, 42, 7086-7098.

12 J. H. van Esch and B. L. Feringa, Angew. Chem., Int. Ed., 2000, 39, 2263-2266.

13 W. Ji, G. Liu, M. Xu, X. Dou and C. Feng, Chem. Commun., 2014, 50, 15545-15548.

14 N. Kameta, M. Masuda and T. Shimizu, Chem. Commun., 2015, 51, 11104-11107.

15 H. Wang, C. Yang, L. Wang, D. Kong, Y. Zhang and Z. Yang, Chem. Commun., 2011, 47, 4439-4441.

16 S. Yamamichi, Y. Jinno, N. Haraya, T. Oyoshi, H. Tomitori, K. Kashiwagi and M. Yamanaka, Chem. Commun., 2011, 47, 10344-10346.

17 A. Tanaka, Y. Fukuoka, Y. Morimoto, T. Honjo, D. Koda, M. Goto and T. Maruyama, J. Am. Chem. Soc., 2015, 137, 770-775.

18 M. Bibian, J. Mangelschots, J. Gardiner, L. Waddington, M. M. Diaz Acevedo, B. G. De Geest, B. Van Mele, A. Madder, R. Hoogenboom and S. Ballet, J. Mater. Chem. $B, 2015,3,759-765$.

19 E. Ye, P. L. Chee, A. Prasad, X. Fang, C. Owh, V. J. J. Yeo and X. J. Loh, Mater. Today, 2014, 17, 194-202.

20 M. Singh, S. Kundu, M. A. Reddy, V. Sreekanth, R. K. Motiani, S. Sengupta, A. Srivastava and A. Bajaj, Nanoscale, 2014, 6, 12849-12855.

21 R. Tian, J. Chen and R. Niu, Nanoscale, 2014, 6, 34743482 .

22 K. J. Skilling, F. Citossi, T. D. Bradshaw, M. Ashford, B. Kellam and M. Marlow, Soft Matter, 2014, 10, 237-256.

23 K. Basu, A. Baral, S. Basak, A. Dehsorkhi, J. Nanda, D. Bhunia, S. Ghosh, V. Castelletto, I. W. Hamley and A. Banerjee, Chem. Commun., 2016, 52, 5045-5048.

24 G. Fichman and E. Gazit, Acta Biomater., 2014, 10, 16711682.

25 F. Versluis, J. H. van Esch and R. Eelkema, Adv. Mater., 2016, 28, 4576-4592.

26 M. Suzuki and K. Hanabusa, Chem. Soc. Rev., 2009, 38, 967975.

27 J. Bachl, J. Mayr, F. J. Sayago, C. Cativiela and D. Diaz Diaz, Chem. Commun., 2015, 51, 5294-5297.

28 G. M. Peters and J. T. Davis, Chem. Soc. Rev., 2016, 45, 31883206.

29 A. Y.-Y. Tam and V. W. W. Yam, Recent advances in metallogels, Chem. Soc. Rev., 2013, 42, 1540-1567.

30 P. K. Vemula and G. John, Acc. Chem. Res., 2008, 41, 769782.

31 X. Du, J. Zhou, J. Shi and B. Xu, Chem. Rev., 2015, 115, 1316513307.

32 J. Boekhoven, A. M. Brizard, M. C. A. Stuart, L. Florusse, G. Raffy, A. Del Guerzo and J. H. van Esch, Chem. Sci., 2016, 7, 6021-6031.

33 H. P. R. Mangunuru, H. Yang and G. Wang, Chem. Commun., 2013, 49, 4489-4491.

34 S. Datta and S. Bhattacharya, Chem. Soc. Rev., 2015, 44, 55965637.

35 Z. Yang, G. Liang, M. Ma, A. S. Abbah, W. W. Lu and B. Xu, Chem. Commun., 2007, 843-845. 
36 J. Liu, Z. Sun, Y. Yuan, X. Tian, X. Liu, G. Duan, Y. Yang, L. Yuan, H. C. Lin and X. Li, ACS Appl. Mater. Interfaces, 2016, 8, 6917-6924.

37 A. M. Vibhute, V. Muvvala and K. M. Sureshan, Angew. Chem., Int. Ed., 2016, 55, 7782-7785.

38 M. Delbianco, P. Bharate, S. Varela-Aramburu and P. H. Seeberger, Chem. Rev., 2016, 116, 1693-1752.

39 Y. Koshi, E. Nakata, H. Yamane and I. Hamachi, J. Am. Chem. Soc., 2006, 128, 10413-10422.

40 G. Wang, S. Cheuk, H. Yang, N. Goyal, P. V. N. Reddy and B. Hopkinson, Langmuir, 2009, 25, 8696-8705.

41 N. Goyal, S. Cheuk and G. Wang, Tetrahedron, 2010, 66, 5962-5971.

42 G. Wang, N. Goyal, H. P. R. Mangunuru, H. Yang, S. Cheuk and P. V. N. Reddy, J. Org. Chem., 2015, 80, 733-743.

43 C. C. Tsai, W. T. Chuang, Y. F. Tsai, J. T. Li, Y. F. Wu and C. C. Liao, J. Mater. Chem. B, 2013, 1, 819-827.

44 M. Meldal and C. W. Tornøe, Chem. Rev., 2008, 108, 29523015.

45 P. Thirumurugan, D. Matosiuk and K. Jozwiak, Chem. Rev., 2013, 113, 4905-4979.
46 H. C. Kolb, M. G. Finn and K. B. Sharpless, Angew. Chem., Int. Ed., 2001, 40, 2004-2021.

47 Y. M. Chabre and R. Roy, Chem. Soc. Rev., 2013, 42, 46574708.

48 V. K. Tiwari, B. B. Mishra, K. B. Mishra, N. Mishra, A. S. Singh and X. Chen, Chem. Rev., 2016, 116, 3086-3240.

49 X. P. He, Y. L. Zeng, Y. Zang, J. Li, R. A. Field and G. R. Chen, Carbohydr. Res., 2016, 429, 1-22.

50 R. Balamurugan, Y. S. Zhang, S. Fitriyani and J. H. Liu, Soft Matter, 2016, 12, 5214-5223.

51 Y. Huang, Y. Zhang, Y. Yuan and W. Cao, Tetrahedron, 2015, 71, 2124-2133.

52 H. P. R. Mangunuru, J. R. Yerabolu, D. Liu and G. Wang, Tetrahedron Lett., 2015, 56, 82-85.

53 H. P. R. Mangunuru, J. R. Yerabolu and G. Wang, Tetrahedron Lett., 2015, 56, 3361-3364.

54 A. Hemamalini and T. Mohan Das, New J. Chem., 2013, 37, 2419-2425.

55 K. Ghosh, A. Panja and S. Panja, New J. Chem., 2016, 40, 3476-3483.

56 H. Surya Prakash Rao, M. Kamalraj, J. Swain and A. K. Mishra, RSC Adv., 2014, 4, 12175-12181. 